\title{
Exclusive breastfeeding for the first six months of life and its associated factors among children age 6-24 months in Burao district, Somaliland
}

Abdiasis Jama'1, Hailay Gebreyesus ${ }^{1 *}$, Tewolde Wubayehu², Tsigehana Gebregyorgis ${ }^{1}$, Mebrahtu Teweldemedhin ${ }^{3}$, Tesfay Berhe ${ }^{1}$ and Negasi Berhe ${ }^{1}$

\begin{abstract}
Background: Adequate nutrition during early childhood ensures growth and development of children and breast milk is better than any other products given to a child. However, studies on exclusive breastfeeding practice are limited in Somaliland. Therefore, this study was aimed to assess exclusive breastfeeding for the first 6 months of life and its associated factors among children 6-24 months of age in Burao district, Somaliland.

Methods: A community-based cross-sectional study was conducted from 26 August to 10 October 2018, in Burao district among randomly, selected 464 mothers with children 6-24 months of age. Data were collected through face-to-face interview using pretested structured questionnaire.

Results: The prevalence of exclusive breastfeeding was 20.47\% (95\% Cl 18.84, 23.63\%). Exclusive breastfeeding practice was associated with: having female child (AOR 0.48; $95 \%$ Cl 0.29, 0.80)), lack of formal education (AOR 0.32; $95 \% \mathrm{Cl} 0.19,0.53$ ), household monthly income $100 \$-200 \$$ (AOR $0.35 ; 95 \% \mathrm{Cl} 0.18,0.68$ ), lack of husband's support (AOR 0.32; $95 \% \mathrm{Cl} 0.19,0.53$ ), and mothers who were not counselled on breastfeeding during antenatal care ( $A O R=0.33 ; 95 \% \mathrm{Cl} 0.16,0.66)$.
\end{abstract}

Conclusions: Exclusive breastfeeding practice was very low as compared to recommendations of infant and young child practice (IYCF) which recommends children to exclusively breastfeed for the first 6 months of life. Exclusive breastfeeding practice was associated with a mother's lack of formal education, monthly income less than 100\$, being a female child, lack of advice on exclusive breastfeeding during antenatal care and lack of husband support. The promotion of education for women, husband's engagement, encouraging antenatal care follow-up and counseling of exclusive breastfeeding during antenatal care was recommended to improve exclusive breastfeeding practice.

Keywords: Exclusive breastfeeding practice, Children age 6-24 Burao, Somaliland

\footnotetext{
* Correspondence: ghailay2015@gmail.com

${ }^{1}$ Department of Public Health, College of Health Science, Aksum University,

Aksum, Ethiopia

Full list of author information is available at the end of the article
}

(c) The Author(s). 2020 Open Access This article is distributed under the terms of the Creative Commons Attribution 4.0 International License (http://creativecommons.org/licenses/by/4.0/), which permits unrestricted use, distribution, and reproduction in any medium, provided you give appropriate credit to the original author(s) and the source, provide a link to the Creative Commons license, and indicate if changes were made. The Creative Commons Public Domain Dedication waiver (http://creativecommons.org/publicdomain/zero/1.0/) applies to the data made available in this article, unless otherwise stated. 


\section{Background}

According to the definition the World Health Organization (WHO), Exclusive breastfeeding (EBF) is the situation in which an infant receives only breast milk from his/her mother or a wet nurse for the first 6 months and no other solids or liquids with the exception of drops or syrups consisting of vitamins, minerals, supplements, or medicines [1].

Globally, about $40 \%$ of infants were exclusively breastfed and this is expected to rise to $50 \%$ by 2025 . Although the rates of EBF for the past two decades have been increasing, it is still a long road to achieve the $100 \%$ global target coverage recommended by UNICEF. This is evident in the current low prevalence of EBF in the developing world particularly in West and Central Africa which happen to have one of the highest rates of infant malnutrition in the world $[2,3]$.

Despite the WHO recommendations and benefits of EBF, worldwide, only $39 \%$ of newborns were put to the breast within $1 \mathrm{~h}$ of birth, and only $37 \%$ of infants were exclusively breastfed. In Sub-Saharan Africa, $20 \%$ of women reported exclusive breastfeeding of their last born infant. In North Africa, the rate of exclusive breastfeeding is 41, 44\% in Asia, and the lowest in Latin America at $30 \%[4,5]$.

Overall poor breastfeeding practice, particularly exclusive breastfeeding had been broadly documented in the developing countries and only about $25 \%$ of infants in Africa were exclusively breastfed. Additionally, $6 \%$ of infants in developing countries were never breastfed [6]. Globally, of 56 million infants, approximately 22 million were exclusively breastfed, while over 34 million children were not. Previous studies showed that $80 \%$ of these children who did not benefit from exclusive breastfeeding in developing countries reside in only 29 countries. From these 29 countries, the 10 large countries including Ethiopia have two-thirds of the approximate numbers of non-exclusively breastfed children [7-9].

In Somaliland, malnutrition is a huge public health problem, negatively affecting the growth, development, and survival of young children. Malnutrition has been aggravated by poor infant and young child feeding practices and other contributing factors including the long-term armed conflict and insecurity, and the breakdown in social and public services. Recurrent droughts and flooding also seriously affecting food security. Existing evidence show that infant feeding practices in Somaliland are alarming and only $13 \%$ of the infants have been exclusively breastfed [8]. Exclusive breastfeeding was challenged by a lack of knowledge and different sociocultural beliefs; the incorrect beliefs that breastfeeding mothers are unable to produce enough milk to exclusively breastfeed their child for the first 6 months of life and that society believes that breastfeeding mothers look older than their age. The other barriers include, societal or peer pressure to bottle feed their child. In order to overcome this problem, the Ministry of Health of Somalia and UNICEF has been working together to improve the infant and young child feeding practices.

Exclusive breastfeeding for the first 6 months is one of the infant and young child feeding practices recommended by WHO which can be appropriately assessed by this lifelong EBF practice over time point EBF practice, because the time point EBF practice is mostly assessed by $24 \mathrm{~h}$ recall which cannot give us guarantee about the 6 month course EBF practice.

The low prevalence of EBF in most developing countries is attributed to various maternal and child-related factors such as place of residence, sex, age of the child, number of births and space between children, mother working outside home, maternal age and educational level, economic status, mothers' domestic work burden, access to mass media, maternal healthcare access and use, and maternal knowledge on infant and young child feeding practices $[4,10-16]$.

There is a paucity of scientific research that investigate the prevalence of EBF and factors affecting EBF in Somaliland, particularly in the study area. Therefore, this study was aimed to determine the exclusive breastfeeding practice for the first 6 months and its associated factors among mothers having children 6-24 months of age in Burao, Somaliland.

\section{Methods \\ Study design and setting}

This community-based cross-sectional study was conducted among children aged 6-24 months of age in Burao district, Somaliland, $260 \mathrm{~km}$ away from Hargeisa the capital city of Somaliland. The climate of the region is semi-arid and it has a total population of 406,866 [17]. Regarding the health facilities, the city has eight hospitals (two public hospitals and six private hospitals), three health centers, and more than 10 private clinics. The study was conducted from 26 August to 10 October, 2018.

\section{Sample size and sampling technique}

Sample size was determined using single population proportion formula $\left[\mathrm{n}=\left[(\mathrm{Za} / 2)^{2 *} \mathrm{P}(1-\mathrm{P})\right] / \mathrm{d}^{2}\right]$ by assuming $95 \%$ confidence level of $Z \alpha / 2=1.96$, estimated prevalence of exclusive breastfeeding $(P)$ as $12.8 \%$ [17] from study done in Somaliland, 5\% margin of error (d).

The final sample size was 474 mothers. From the five zones in Burao town, two zones were selected by lottery method. Each zone had 12 villages and four villages were selected randomly from each selected zone. The sample size was allocated into the selected eight villages proportionally to the number of mothers with children between 6 and 24 months of age. Systematic random sampling technique was used to select respondent to be interviewed 
within the selected villages. For those who have had more than two eligible respondents in the same house, lottery method was applied to choose one amongst.

\section{Data collection tools and quality assurance procedures}

Data were collected using structured interviewer administered questionnaire (Additional file 1) which is adopted and modified from different literatures $[1,12,15,18]$. The questionnaire was first prepared in English and translated to Somali and finally retranslated back to English by a person who can speak both languages. The questionnaire consisted of sociodemographic factors (age, marital status, educational level, monthly income, sex of the child); obstetric and health service related factors (place of delivery, ANC visit, number of ANC visit, postnatal services, colostrum feeding) and psychosocial factors (husband support, family support, knowledge of the mother on EBF). A pretest among 24 (5\%) of the sample prior to the actual data collection was carried out in nearby village other than those included in the actual study. Mothers who had 6-24 months old children were asked about their lifelong (6 month course) EBF practice using their recall response. Mothers are categorized as practicing EBF practice if they exclusively breastfeed their child for 6 months, but if they exclusively breastfeed for less than 6 months they are categorized as they don't practice exclusive breastfeeding. To assess knowledge about EBF, respondents were asked 10 questions on importance of EBF, duration of EBF, contents of breast milk. Respondents that correctly responded $>7$ knowledge questions were considered as having good knowledge on EBF, and those who respond $<7$ knowledge questions are categorized as having poor knowledge on exclusive breastfeeding. Three trained accountants and five information technicians (IT) collected the data. Three trained public health professionals and the principal investigator supervised the data collection process.

\section{Data processing and analysis}

Data were coded and entered into SPSS Version 21 software for analyses. Descriptive analysis including frequency distribution, proportion and mean was performed to summarize the characteristics of the study subjects. To identify factors associated with exclusive breastfeeding practice, firstly bivariable logistic regression was performed. Subsequently, significant variables in the bivariable analysis $(p$ - value $<0.05)$ were incorporated into the multivariable logistic regression. Statistical significance was declared at $p<0.05$ and the corresponding 95\% CI.

\section{Results}

\section{Sociodemographic characteristics of the study} participants

Four hundred sixty-four mothers who had children between 6 to 24 months of age were included in the study making the response rate of $98 \%$. The mean $( \pm$ SD) age of the study participants was $27.10(+5.1)$ years. Two hundred seventy-six (59.5\%) of the study participants were in the age range of 25-34 years followed by those in the age range of 15-24 years which accounts for 140 $(30.2 \%)$. Nearly half of the women $224(48.2 \%)$ had formal education. Two hundred fifty-four $(54.7 \%)$ of the mothers earned an average monthly income of less than the $246 \$$ (Table 1).

\section{Obstetric history and health service related factors}

Of the 464 mothers who participated in the study, 194 $(41.8 \%)$ of the mothers had more than three living children at the time of the study. The majority $(72.2 \%)$ of the mothers had at least one antenatal care (ANC) follow up during their last pregnancy, of which (77\%) had four and above ANC visits. Close to one third (28.2\%) of the mothers had at least one child death. Close to threefourth $(73.1 \%)$ of the mothers gave birth at a health institution. Of the 464 mothers, $79.7 \%$ had received advice on breastfeeding (Table 2).

\section{Psychosocial factors}

Of the 464 mothers who participated in the study, only 163 (35.1\%) were receiving support from their husbands. However, 155 (33.4\%) of the mothers reported that they received help from other family members. More than half of the mothers $265(57.1 \%)$ had poor knowledge about exclusive breastfeeding (Table 3).

\section{Exclusive breastfeeding practices}

The prevalence of exclusive breastfeeding practice was 20.47\% (95\% CI 18.84, 23.63\%). Almost all the mothers had breastfed at least once in their life time to their youngest child. About 419 (90.3\%) of the mothers were still breastfeeding their children during the study period. From all respondents, only $36(7.8 \%)$ of the mothers expressed and discarded their colostrum; 18 (50\%) of these mothers who expressed believed that colostrum causes abdominal cramps (Table 4).

\section{Factors associated with exclusive breastfeeding practices} According to the multivariable logistic regression analysis, educational level of the mother, average family monthly income, sex of the child, ANC visit, and support from husband were identified as statistically significant factors for exclusive breastfeeding practice. Mothers who did not attend formal education and mothers who attended elementary schools were 68 and 52\% less likely to exclusively breastfeed their children than those who attended secondary school and above (AOR 0.32; 95\% CI 0.19, 0.53 and AOR 0.48; 95\% CI 0.29, 0.80).

The average family monthly income was another factor that was found statistically associated with exclusive breastfeeding. Mothers with monthly house hold income of $100 \$-$ $200 \$$ were $65 \%$ less likely to exclusively breastfeed their 
Table 1 Sociodemographic characteristics of mothers having children aged 6-24 months from Burao town, Somaliland, 2019 ( $n=464)$

\begin{tabular}{|c|c|c|c|}
\hline Variable & Category & Frequency & Percentage \\
\hline \multirow[t]{3}{*}{ Age } & $15-24$ & 140 & 30.2 \\
\hline & $25-34$ & 276 & 59.5 \\
\hline & $\geq 35$ & 48 & 10.3 \\
\hline \multirow[t]{3}{*}{ Marital status } & Married & 401 & 86.4 \\
\hline & Divorced & 46 & 9.9 \\
\hline & Widowed & 17 & 3.7 \\
\hline \multirow[t]{3}{*}{ Level of education of the mother } & No formal education & 240 & 51.7 \\
\hline & Elementary school & 106 & 22.8 \\
\hline & Higher school and above & 118 & 25.4 \\
\hline \multirow[t]{5}{*}{ Occupation status of the mother } & House wife & 318 & 68.5 \\
\hline & Merchant & 64 & 13.8 \\
\hline & Private company employed & 10 & 2.2 \\
\hline & Government employed & 57 & 12.3 \\
\hline & Daily labor & 15 & 3.2 \\
\hline \multirow[t]{3}{*}{ Level of education of the father } & No formal education & 90 & 19.4 \\
\hline & Elementary school & 152 & 32.8 \\
\hline & Higher school and above & 222 & 47.8 \\
\hline \multirow[t]{5}{*}{ Occupation status of the father } & Merchant & 125 & 26.9 \\
\hline & Private company employed & 143 & 30.8 \\
\hline & Government employed & 109 & 23.5 \\
\hline & Daily labor & 85 & 18.3 \\
\hline & Other ${ }^{a}$ & 2 & 0.5 \\
\hline \multirow[t]{3}{*}{ Family monthly income } & $100-200 \$$ & 185 & 39.9 \\
\hline & $201-400 \$$ & 172 & 37.1 \\
\hline & $>400 \$$ & 107 & 23.1 \\
\hline \multirow[t]{2}{*}{ Sex of the child } & Male & 224 & 48.3 \\
\hline & Female & 240 & 51.7 \\
\hline
\end{tabular}

${ }^{\mathrm{a} O t h e r}=$ student

children than mothers with monthly house hold income of $400 \$$ and above (AOR 0.35; 95\% CI 0.18, 0.67). This study revealed that female child was $52 \%$ less likely to exclusively breastfeed than male child (AOR 0.48; 95\% CI 0.29, 0.80).

Attending an ANC visit was another factor found significantly associated with exclusive breastfeeding practice Mothers who received an ANC visit were 67\% less likely to exclusively breastfeed their children than those who had no ANC (AOR 0.33; 95\% CI 0.16, 0.66). Additionally, Mothers who did not get support from their husbands were $68 \%$ less likely to exclusively breastfeed their children than those who received support from their husband (AOR 0.32; 95\% CI 0.19, 0.53) (Table 5).

\section{Discussion}

The prevalence of exclusive breastfeeding in our study is lower than the findings of the Somaliland national policy of exclusive breastfeeding [17], and a study done in
Indonesia which shows EBF as 26.2\% [19] and 64\% in Ghana [20]. Additionally, our finding is lower than the previous study conducted $57.6 \%$ in a southern part of Ethiopia [4]. This variation might be due to the socioeconomic status of the participants and or access to a health facility and most of the other studies have a lower sample size compared to this study. Study setting difference might contribute to this difference like the study done from Addis Ababa, Ethiopia which was a health facility-based study and could contribute to an increased awareness about EBF practice by the counseling provided during an ANC visit. Age differences between the study subjects might also be a reason because children less than 6 months of age were included in the study from Ghana [20]. Additionally, the low EBF rates in our study might be due to definition of EBF by which this study uses lifelong EBF other than the point time exclusive breastfeeding. 
Table 2 Obstetric history and health service-related factors of mothers having children aged 6-24 months from Burao town, Somaliland, 2019 ( $n=464)$

\begin{tabular}{|c|c|c|c|}
\hline Variable & Category & Frequency & Percentage \\
\hline \multirow[t]{2}{*}{ Age of the mother at first marriage } & $15-24$ & 415 & 89.4 \\
\hline & $25-34$ & 49 & 10.6 \\
\hline \multirow[t]{2}{*}{ Age of the mother in first delivery } & $15-24$ & 355 & 76.5 \\
\hline & $25-34$ & 109 & 23.5 \\
\hline \multirow[t]{3}{*}{ Parity } & 1 & 145 & 31.2 \\
\hline & 2 & 125 & 26.9 \\
\hline & 3 and above & 194 & 41.8 \\
\hline \multirow[t]{2}{*}{ ANC visit } & Yes & 335 & 72.2 \\
\hline & No & 129 & 27.8 \\
\hline \multirow[t]{2}{*}{ Number of ANC visits } & Less than 4 & 77 & 23 \\
\hline & 4 and above & 258 & 77 \\
\hline \multirow[t]{3}{*}{ Receiving information during ANC about exclusive breastfeeding } & Yes & 246 & 73.4 \\
\hline & No & 43 & 12.8 \\
\hline & I do not remember & 46 & 13.7 \\
\hline \multirow[t]{2}{*}{ Place of delivery of the baby } & Home & 126 & 27.1 \\
\hline & Health facility & 338 & 72.9 \\
\hline \multirow[t]{2}{*}{ Assistant of home delivery } & TTBA & 93 & 73.8 \\
\hline & TBA & 33 & 26.2 \\
\hline \multirow[t]{2}{*}{ Postnatal care } & Yes & 370 & 79.7 \\
\hline & No & 94 & 20.3 \\
\hline \multirow[t]{3}{*}{ Vaccination of the child } & Yes & 454 & 97.8 \\
\hline & No & 10 & 2.2 \\
\hline & Do not know & 148 & 31.9 \\
\hline \multirow[t]{2}{*}{ Screened for HIV } & Yes & 387 & 83.4 \\
\hline & No & 77 & 16.6 \\
\hline
\end{tabular}

This study revealed that mothers who did not attend formal education and mothers who attended elementary schools were less likely to exclusively breastfeed their children than those who attended secondary school and above. However uneducated mothers exclusively breastfeed their child in a study done in Ethiopia [7]. Another study showed no association between the level of education and practice of exclusive breastfeeding in Somalia [17]. The association found in our study might be due to the role of education in improving awareness about EBF practice and increasing health seeking behaviors like attending an ANC visit.

In this study, mothers with a monthly house hold income of $100 \$-200 \$$ were $65 \%$ less likely to exclusively

Table 3 Exclusive breastfeeding practice among mothers having children aged 6-24 months from Burao town Somaliland 2019

$(n=464)$

\begin{tabular}{|c|c|c|c|}
\hline Variable & Category & Frequency & Percentage \\
\hline \multirow[t]{2}{*}{ Squeeze and discard the first milk } & Yes & 36 & 7.8 \\
\hline & No & 428 & 92.2 \\
\hline \multirow[t]{3}{*}{ Reason for squeeze and throw out } & To initiate milk production & 16 & 44.4 \\
\hline & Dirty & 2 & 5.6 \\
\hline & Colostrum causes abdominal cramp & 18 & 50 \\
\hline \multirow[t]{2}{*}{ Continuing to breastfeed } & Yes & 419 & 90.3 \\
\hline & No & 45 & 9.7 \\
\hline
\end{tabular}


Table 4 Psychosocial and knowledge factors of mothers having children aged 6-24 months from Burao town Somaliland 2019 ( $n=$ 464)

\begin{tabular}{|c|c|c|c|}
\hline Variable & Category & Frequency & Percentage \\
\hline \multirow[t]{2}{*}{ Help from father } & Yes & 163 & 35.1 \\
\hline & No & 301 & 64.9 \\
\hline \multirow[t]{2}{*}{ Type of help } & Breastfeeding the child (consultation) & 150 & 92 \\
\hline & Other & 13 & 8 \\
\hline \multirow[t]{2}{*}{ Help from other family } & Yes & 155 & 33.4 \\
\hline & No & 309 & 66.6 \\
\hline \multirow[t]{2}{*}{ Breastfeeding knowledge } & Good knowledge & 199 & 42.9 \\
\hline & Low knowledge & 265 & 57.1 \\
\hline
\end{tabular}

* Helping workload in the house, preparing and providing food for the lactating mother

breastfeed their children than those with monthly house hold income of $400 \$$ and above. A study conducted in Kenya also stated that income has positive association with exclusive breastfeeding [12]. The observed association might be due to the role of income in improving exposure to various media that can improve their knowledge on EBF practice.

Sex of the child was significantly associated with exclusive breastfeeding in this study. A female child was 52\% less likely to be exclusively breastfeed than male child. A similar finding was found in a study done in India [21]. However, this finding is not consistent with study done in Nigeria [15]. The association found in this study might be due to the values given for males and females in the community. Mostly, having a baby boy resulted in feeling more pride for the family and due to this, a mother might focus more on baby boys than girls while they feed.

This study indicated that receiving antenatal care was associated with exclusively breastfeed, similar to the positive association observed in Tanzania. This could be due to mothers attending antenatal services being exposed to information about exclusive breastfeeding.

Additionally, support from a husband was associated with exclusive breastfeeding practice. Mothers who did not get support from their husbands were $68 \%$ less likely to exclusively breastfeed their children than those who got support from their husband. A study conducted in Hong Kong is in line with the finding of this study [18]. This might be due to the role of husband support in promoting exclusive breastfeeding. As mothers are asked to remember and respond the duration of exclusive

Table 5 Factors associated with excusive breastfeeding among mothers having children aged 6-24 months old in Burao, Somaliland, 2019 ( $n=464)$

\begin{tabular}{|c|c|c|c|c|c|}
\hline \multirow[t]{2}{*}{ Variable } & \multirow[t]{2}{*}{ Categories } & \multicolumn{2}{|c|}{ Exclusive breastfeeding } & \multicolumn{2}{|l|}{ Odds Ratio (95\% Cl) } \\
\hline & & Yes & No & Crude Odds Ratio & Adjusted Odds Ratio \\
\hline \multirow[t]{3}{*}{ Educational level of the mother } & No formal education & $30(6.5 \%)$ & $210(45.3 \%)$ & $0.27(0.13,0.55)$ & $0.32(0.19,0.53)^{*}$ \\
\hline & Elementary school & $25(5.4 \%)$ & $81(17.5 \%)$ & $0.57(0.33,0.97)$ & $0.48(0.29,0.80)^{*}$ \\
\hline & Higher schools and above & $40(8.6 \%)$ & $78(17.8 \%)$ & 1 & 1 \\
\hline \multirow[t]{3}{*}{ Monthly income } & $100 \$-200 \$$ & $24(5.2 \%)$ & $161(34.7 \%)$ & $0.28(0.16,0.50)$ & $0.35(0.18,0.67)^{*}$ \\
\hline & $201 \$-400 \$$ & $34(7.3 \%)$ & $138(29.7 \%)$ & $0.47(0.27,0.80)$ & $0.56(0.30,1.00)$ \\
\hline & $>400 \$$ & $37(8 \%)$ & $70(15.1 \%)$ & 1 & 1 \\
\hline \multirow[t]{2}{*}{ Sex of the child } & Male & $57(12.3 \%)$ & $167(36 \%)$ & 1 & 1 \\
\hline & Female & $38(8.2 \%)$ & $202(43.5 \%)$ & $0.55(0.35,0.87)$ & $0.48(0.29,0.80)^{*}$ \\
\hline \multirow[t]{2}{*}{ ANC visit } & Yes & $84(18.1 \%)$ & $251(54.1 \%)$ & 1 & 1 \\
\hline & No & $11(2.4 \%)$ & $118(25.4 \%)$ & $0.27(0.14,0.54)$ & $0.33(0.16,0.66)^{*}$ \\
\hline \multirow[t]{2}{*}{ Support from husband } & Yes & $53(11.4 \%)$ & $110(23.7 \%)$ & 1 & 1 \\
\hline & No & 42 (9.1\%) & $259(55.8 \%)$ & $0.34(0.21,0.53)$ & $0.32(0.19,0.53)^{*}$ \\
\hline \multirow[t]{2}{*}{ Place of birth } & Home & $16(3.4 \%)$ & $110(23.7 \%)$ & $0.47(0.26,0.85)$ & $0.69(0.36,1.31)$ \\
\hline & Health facility & 79 (17\%) & $259(55.8 \%)$ & 1 & 1 \\
\hline
\end{tabular}

${ }^{\prime}$ significant at $p$ value $<0.05$; Reference Category $=1.00$ 
breastfeeding retrospectively [22], recall bias is one of the limitations of this study.

\section{Conclusion}

The prevalence of exclusive breastfeeding was very low compared to recommendations of infant and young child practice (IYCF) which recommends children be exclusively breastfed for the first 6 months of life. Mother's lack of formal education, income less than $100 \$$ per month, being female child, ANC visit, and lack of support from husband were statistically associated with low exclusive breastfeeding practice. Promotion of women's education, husbands' engagement, encouraging antenatal care and exclusive breastfeeding counseling during antenatal care were recommended to improve exclusive breastfeeding practice.

\section{Supplementary information}

Supplementary information accompanies this paper at https://doi.org/10. 1186/s13006-020-0252-7.

Additional file 1. Questionnaire.

\section{Abbreviations}

ANC: Antenatal Care; EBF: Exclusive Breastfeeding; EDHS: Ethiopian Demographic Health Survey; HEW: Health Extension Workers; HH: House Hold; IYCF: Infancy and Young Children Feeding; MCH: Maternal and Child Health; MPH: Master of Public Health; SNNPR: Southern Nations Nationalities and Peoples' Region; TBA: Traditional Birth Attendant; TTBA: Trained traditional birth attendant; VIF: Variance Inflation Factor; WHO: World Health Organization

\section{Acknowledgements}

Our deepest gratitude goes to Aksum University College of Health Sciences for financial support in conducting this work. Our heartfelt thank also goes to Somaliland Burao regional health office; all study participants and data collectors for their cooperation during this study.

\section{Authors' contributions}

Conceived and designed the study: AJ, TW, TG and HG. Coordinated the field work; AJ, TW, TG and HG. Analyzed the data and wrote the manuscript: AJ, TW, TG, HG, MT, TB and NB. All authors also read and approve the final manuscript.

\section{Funding}

This work was supported by Aksum University College of Health Sciences.

\section{Availability of data and materials}

The datasets on which conclusion was made is available in the form of Microsoft Excel. It is available on reasonable request.

\section{Ethics approval and consent to participate}

Ethical clearance was obtained from ethical review committee of Aksum University College of health sciences and comprehensive specialized hospital (IRC128/2017). A permission letter was obtained from Burao town health office. Written informed consent was obtained from each study participant and their parents/guardians (for those under 18 years) after clear explanation about the purpose, benefit, risk, confidentiality of the information and voluntary nature of participation in the study. All of the study participants were reassured that they will be anonymous. Names or any personal identifiers were not recorded. Respondents were clearly told about the study and the variety of information needed from them. They had been given the chance to ask anything about the study and made free to refuse to participate or stop the interview at any moment they want if that was their choice. Data was kept in the form of file in secure place or PC where no one access except the investigator.
Consent for publication

Not applicable.

\section{Competing interests}

The authors declare that they have no competing interests.

\section{Author details}

${ }^{1}$ Department of Public Health, College of Health Science, Aksum University, Aksum, Ethiopia. ${ }^{2}$ School of Medicine, College of Health Science, Aksum University, Aksum, Ethiopia. ${ }^{3}$ Department of Medical Laboratory Sciences, College of Health Science, Aksum University, Aksum, Ethiopia.

Received: 12 February 2019 Accepted: 21 January 2020

Published online: 30 January 2020

\section{References}

1. Elyas L, Mekasha A, Admasie A, Assefa E. Exclusive breastfeeding practice and associated factors among mothers attending private pediatric and child clinics, Addis Ababa, Ethiopia: a cross-sectional study. Int J Pediatr. 2017; 2017(8546192):9. https://doi.org/10.1155/2017/8546192.

2. Mensah KA, Acheampong E, Anokye FO, Okyere P, Appiah-Brempong E, Adjei RO. Factors influencing the practice of exclusive breastfeeding among nursing mothers in a peri-urban district of Ghana. BMC Res Notes. 2017;10:466.

3. Cai X, Wardlaw T, Brown DW. Global trends in exclusive breastfeeding. Int Breastfeed J. 2012;7:12

4. Reddy S, Abuka T. Determinants of exclusive breastfeeding practice among mothers of children under two years old in Dilla Zuria District, Gedeo zone, SNNPR, Ethiopia, 2014. J Pregnancy Child Health. 2016;3:224.

5. Hazir T, Akram DS, Nisar YB, Kazmi N, Agho KE, Abbassi S, et al. Determinants of suboptimal breast-feeding practices in Pakistan. Public Health Nutr. 2013;16:659-72.

6. Lauer JA, Betrán AP, Victora CG, De Onís M, Barros AJ. Breastfeeding patterns and exposure to suboptimal breastfeeding among children in developing countries: review and analysis of nationally representative surveys. BMC Med. 2004;2:26.

7. Tsegaye M, Ajema D, Shiferaw S, Yirgu R. Level of exclusive breastfeeding practice in remote and pastoralist community, Aysaita woreda, Afar, Ethiopia. Int Breastfeed J. 2019;14:6.

8. Security F, Unit-Somalia NA. National Micronutrient and anthropometric nutrition survey. Geneva: World Health Organization and United Nations Children's Fund; 2009. p. 2009.

9. Pieh-Holder KL. Birthing support and breastfeeding initiation in Somaliland. Afr J Midwifery Womens Health. 2011:5:196-201.

10. Seifu W, Assefa G, Egata G. Prevalence of exclusive breastfeeding and its predictors among infants aged six months in Jimma town, Southwest Ethiopia, 2013. J Pediatr Neonatal Care. 2014;1 (3):00017.

11. Ogbo FA, Agho KE, Page A. Determinants of suboptimal breastfeeding practices in Nigeria: evidence from the 2008 demographic and health survey. BMC Public Health. 2015;15:259.

12. Murage KE, Madise N, Forso JC, Kyobutungi C, Mutua M, Gitau TM. Patterns and determinants of breastfeeding and complementary feeding practices in urban informal settlement. BMC Public Health. 2011;11:396

13. Lok KY, Bai DL, Tarrant M. Predictors of breastfeeding initiation in Hong Kong and mainland China born mothers. BMC Pregnancy Childbirth. 2015;15:286.

14. Mogre V, Dery M, Gaa PK. Knowledge, attitudes and determinants of exclusive breastfeeding practice among Ghanaian rural lactating mothers. Int Breastfeed J. 2016;11:12

15. Agho KE, Dibley MJ, Odiase Jl, Ogbonmwan SM. Determinants of exclusive breastfeeding in Nigeria. BMC Pregnancy Childbirth. 2011;11:2.

16. Angadi MM, Jawaregowda SK. Gender discrimination in relation to breastfeeding practices in rural areas of Bijapur district, Karnataka. Int J Contemporary Pediatr. 2015;2(4):340-4.

17. Ministry of Health Republic of Somaliland. National Infant and young Child Feeding Strategy for Somaliland 2012-2016.

18. Nelson EA, Chan CW, Yu CM. Breast milk substitutes in Hong Kong. J Paediatr Child Health. 2004:40:350-2.

19. Rahman N, Dewi NU, Fitrasyah SI, Rifai M. Factors related to exclusive breastfeeding among mothers in the city of Palu, Central Sulawesi, Indonesia. Malays J Nutr. 2017;23(2):175-89. 
20. Tampah-Naah AM, Kumi-Kyereme A. Determinants of exclusive breastfeeding among mothers in Ghana: a cross-sectional study. Int Breastfeed J. 2013;8:13.

21. Jain A, Tyagi P, Kaur P, Puliyel J, Sreenivas V. Association of birth of girls with postnatal depression and exclusive breastfeeding: an observational study. BMJ Open. 2014;4:e003545.

22. Mgongo M, Mosha MV, Uriyo JG, Msuya SE, Stray-Pedersen B. Prevalence and predictors of exclusive breastfeeding among women in Kilimanjaro region, Northern Tanzania: a population based cross-sectional study. Int Breastfeed J. 2013;8:12.

\section{Publisher's Note}

Springer Nature remains neutral with regard to jurisdictional claims in published maps and institutional affiliations.

Ready to submit your research? Choose BMC and benefit from:

- fast, convenient online submission

- thorough peer review by experienced researchers in your field

- rapid publication on acceptance

- support for research data, including large and complex data types

- gold Open Access which fosters wider collaboration and increased citations

- maximum visibility for your research: over $100 \mathrm{M}$ website views per year

At BMC, research is always in progress.

Learn more biomedcentral.com/submissions 